\title{
Sol-gel processing of novel bioactive Mg-containing silicate scaffolds for alveolar bone regeneration
}

Journal of Biomaterials Applications 2016, Vol. 30(6) 740-749

(C) The Author(s) 2015

Reprints and permissions: sagepub.co.uk/journalsPermissions.nav DOI: $10.1177 / 0885328215584887$ jba.sagepub.com

@SAGE

\author{
Ourania-Menti Goudouri', Caroline Vogel', Alina Grünewald', \\ Rainer Detsch', Eleana Kontonasaki ${ }^{2}$ and Aldo R Boccaccini'
}

\begin{abstract}
Periodontal tissue regeneration is an important application area of biomaterials, given the large proportion of the population affected by periodontal diseases like periodontitis. The aim of this study was the synthesis of a novel porous bioceramic scaffold in the $\mathrm{SiO}_{2}-\mathrm{CaO}-\mathrm{MgO}$ system with specific properties targeted for alveolar bone tissue regeneration using a modification of the traditional foam replica technique. Since bioceramic scaffolds are considered brittle, scaffolds were also coated with gelatin in order to increase their mechanical stability. Gelatin was chosen for its biocompatibility, biodegradability, low-cost, and low immunogenicity. However, gelatin degrades very fast in water solutions. For this reason, two different cross-linking agents were evaluated. Genipin, a non-toxic gardenia extract and the chemical compound I-ethyl-3-(3-dimethylaminopropyl) carbodiimide (EDC) in combination with $\mathrm{N}$-hydroxysuccinimide (NHS), which is also considered non-toxic. The results of the investigation indicated that all scaffolds presented an open, interconnected porosity and pores' sizes in the range of $300-600 \mu \mathrm{m}$, fast apatite-forming ability, biocompatibility, and suitable mechanical stability.
\end{abstract}

\section{Keywords}

Mg-containing silicate scaffolds, sol-gel, alveolar bone regeneration, gelatin, biocompatibility

\section{Introduction}

According to a recent study from Eke et al. ${ }^{1}$ who studied the prevalence, severity, and extent of periodontitis in the adult US population in the years 2009 and 2010 , over $47 \%$ of the sample, representing 64.7 million adults, had periodontitis, distributed as $8.7 \%, 30.0 \%$, and $8.5 \%$ with mild, moderate, and severe periodontitis, respectively. Periodontitis has been defined as the chronic inflammatory disease of the periodontium triggered by bacterial plaque, and is characterized by progressive destruction of the gingiva (gingivitis), alveolar bone, cementum, and periodontal ligament. ${ }^{2,3}$

Currently established techniques for the augmentation of the alveolar bone combine the use of guided tissue regeneration (GTR) with bone grafting materials, osteoinductive substances, biodegradable biomaterials, and topical delivery of growth factors. GTR can be a successful therapeutic method for tooth survival and prognosis, however real bone regeneration cannot be achieved. ${ }^{4}$ Even though autografts are considered the 'gold standard' for periodontal tissue repair, they hold certain drawbacks, including the necessity for a second stage surgery. ${ }^{5}$ Nevertheless, on the basis of current understanding of the molecular and cell biology of periodontal development and regeneration, the introduction of a filler material into a periodontal bony defect is a rather simplistic approach, which is no longer acceptable. ${ }^{6}$ Novel scientific approaches in tissue engineering combine the applications of GTR with an artificial extracellular matrix (ECM), carried

\footnotetext{
'Institute of Biomaterials, University of Erlangen-Nuremberg, Erlangen, Germany

${ }^{2}$ Department of Fixed Prosthodontics, School of Dentistry, Aristotle University of Thessaloniki, Thessaloniki, Greece

Corresponding authors:

Ourania-Menti Goudouri, Dows Institute for Dental Research,

The University of lowa College of Dentistry, lowa city, IA, USA.

Email: ouraniamenti-goudouri@uiowa.edu

Aldo R Boccaccini, Institute of Biomaterials, University of

Erlangen-Nuremberg, 91058 Erlangen, Germany.

Email: aldo.boccaccini@ww.uni-erlangen.de
} 
out by scaffolding materials, which are loaded with cells and signaling molecules such as growth factors, cultured in vitro, and subsequently implanted into tissue defects to induce and direct the growth of new tissue. ${ }^{7-9}$ Favoring cell adhesion and proliferation, scaffolds should provide a suitable 3D environment to ensure new tissue formation. ${ }^{10}$

The most important demands on bone regeneration scaffolds include a porous structure, high biocompatibility as well as a degradation rate matching the bone's regeneration rate. ${ }^{11}$ Magnesium $(\mathrm{Mg})$ is an intracellular earth metal and an essential element for the human body, where about $24 \mathrm{~g}(1 \mathrm{~mol})$ of $\mathrm{Mg}$ ions per $70 \mathrm{~kg}$ of body mass can be found. Owing to its bioactivity, biodegradability, and bioresorbability, elemental $\mathrm{Mg}$ has been proven fundamental for bone remodeling applications and has been used for the fabrication of tissue engineering scaffolds. ${ }^{12,13}$ Elemental $\mathrm{Mg}$ favors adhesion, proliferation, and growth of osteoblastic cells. ${ }^{12,14}$ At the same time $\mathrm{Mg}$ inhibits proliferation of bone resorbing osteoclasts. ${ }^{12}$ Furthermore, $\mathrm{Mg}^{2+}$ divalent cations are associated with the formation of biological appetites, which are essential to promote the bonding between a medical device and the surrounding tissue. ${ }^{12}$

The aim of this study was thus to synthesize a novel $\mathrm{Mg}$-containing scaffold by the combination of the traditional foam replica technique ${ }^{15}$ and the sol-gel method, in order to obtain scaffolds that fulfill the essential requirements for bone tissue regeneration, including appropriate architectural characteristics for tissue ingrowth and vascularization, osteoconductivity, biocompatibility, and mechanical stability. One approach being explored to increase the mechanical properties of highly porous brittle bioceramic scaffolds is the coating with biodegradable polymers. ${ }^{16}$ In this study, this approach was adapted using gelatin.

\section{Materials and methods}

\section{Glass-ceramic synthesis and scaffolds preparation}

The sol-gel technique was used to synthesize scaffolds of the composition (in $\mathrm{mol} \%$ ) $60 \mathrm{SiO}_{2}-30 \mathrm{CaO}-10 \mathrm{MgO}$ $(60 \mathrm{~S} 10 \mathrm{Mg})$. In brief, to prepare the sol, deionized (DI) water was mixed with $2 \mathrm{M} \mathrm{HNO}_{3}$, tetraethyl orthosilicate (TEOS), soluble calcium nitrate tetrahydrate $\left(\mathrm{Ca}\left(\mathrm{NO}_{3}\right)_{2} \cdot 6 \mathrm{H}_{2} \mathrm{O}\right)$, and soluble magnesium nitrate hexahydrate $\left(\mathrm{Mg}\left(\mathrm{NO}_{3}\right)_{2} \cdot 6 \mathrm{H}_{2} \mathrm{O}\right)$ in this order using molar ratios $\mathrm{H}_{2} \mathrm{O}$ /TEOS of $12: 1$ and volume ratios $\mathrm{H}_{2} \mathrm{O}$ / $\mathrm{HNO}_{3}$ of $6: 1$. After complete dissolution of all reactants, polyurethane sponges ( $45 \mathrm{ppi}$ ) were immersed in the solution for $5 \mathrm{~min}$ before being allowed to dry on a Petri dish at room temperature (RT) for $24 \mathrm{~h}$. After $24 \mathrm{~h}$ the foams were again immersed in a suspension of the same composition and airblown so as to remove the excess of liquid. This procedure was repeated nine times. Aging, drying, and chemical stabilization of the prepared scaffolds were carried out in a muffle furnace (Nabertherm L9/12) according to Saravanapavan et al. ${ }^{17,18}$ while the final stabilization temperature was selected to be $860^{\circ} \mathrm{C}$. The specific temperature was selected according to pilot experiments ${ }^{9}$ to ensure the sintering of the scaffolds as well as their biocompatibility.

To enhance their mechanical stability, the scaffolds were coated with 1-ethyl-3-(3-dimethylaminopropyl) carbodiimide / $N$-hydroxysuccinimide (EDC/NHS) cross-linked gelatin. For the gelatin coating, the appropriate amount of gelatin powder from porcine skin (Sigma-Aldrich, USA) was added to DI water keeping constant the gelatin/DI water ratio (gelatin/DI water$=100 / 1)$ and heated up to $50^{\circ} \mathrm{C}$ while being stirred until the gelatin powder was dissolved completely. Subsequently, all scaffolds were immersed in the gelatin solution and the excess of solution was removed by gentle air blow and left to dry overnight at RT. This procedure was repeated twice. After drying, the gelatin coating was cross-linked by immersion in an ethanolic solution of EDC solution at $4^{\circ} \mathrm{C}$ for $24 \mathrm{~h}$. The concentration of EDC was selected to be $25 \mathrm{mM}$ and the molar ratio of EDC/NHS was kept constant at 2.5:1.

\section{Structural and morphological characterization of the scaffolds}

Structural characterization. The structural characterization of the synthesized scaffolds was carried out by X-ray diffractometry (XRD) and Fourier transform infrared spectroscopy (FTIR). In both cases the sintered scaffolds were crashed down, so as to produce powdered samples. The XRD measurements were performed using a D8 ADVANCE X-ray diffractometer (Bruker, Madison) equipped with a VÅNTEC-1 detector. The patterns were recorded in the 2Theta range using $\mathrm{Cu} \mathrm{K} \alpha$ radiation $(\lambda=0.15406 \mathrm{~nm})$ in the range $20^{\circ}-60^{\circ}$ with a step size of $0.014^{\circ} /$ step and accumulation time of $3.0 \mathrm{~s}$ per step. The powders were dispersed in ethanol and the solution was dripped on off-axis cut, low background silicon wafers (Bruker AXS, Germany). All spectra were background corrected and $\mathrm{K} \alpha 2$ was stripped mathematically. FTIR transmittance spectra were performed using an FTIR spectrometer (Nicolet, USA) in the MIR region $\left(4000-400 \mathrm{~cm}^{-1}\right)$ with a resolution of $4 \mathrm{~cm}^{-1}$ by the $\mathrm{KBr}$ pellet technique.

Morphological characterization. Scanning electron microscopy (SEM, Quanta 200, FEI, The Netherlands) was used to characterize the glass-ceramic scaffolds' 
morphology and topography. All scaffolds were gold coated before being observed with SEM. The porosity $p$ of all scaffolds was calculated by the equation:

$$
p=1-\frac{d_{\text {scaffold }}}{d_{\text {solid }}}
$$

where the density $d_{\text {scaffold }}$ of the scaffolds was determined from their mass and dimensions and the $d_{\text {solid }}$ was calculated by the Archimede's method. All measurements were performed in triplicates.

\section{In vitro apatite-forming ability evaluation}

The in vitro apatite-forming ability of all coated and non-coated $60 \mathrm{~S} 10 \mathrm{Mg}$ scaffolds was evaluated by immersion in simulated body fluid (SBF), as proposed by Kokubo et al. ${ }^{19}$ All experiments were performed in triplicates, while the powder to liquid ratio was kept constant at $75 \mathrm{mg} / 50 \mathrm{~mL}$. The samples were kept in a standard shaking incubator $\left(37^{\circ} \mathrm{C}\right.$ and $120 \mathrm{~Hz}$, IKA, Germany) for 1, 3, 6, and 10 days. Finally, the apatite formation on the surface of the struts was evaluated by FTIR spectroscopy and SEM measurements.

\section{In vitro biocompatibility evaluation}

The biocompatibility of all scaffolds with and without coating was evaluated in contact with a stromal cell line (ST2), derived from mouse bone marrow. Six scaffolds from each category were disinfected by immersion in $70 \mathrm{vol} \%$ ethanol solution for $1 \mathrm{~h}$. After disinfection the samples were washed with phosphate-buffered saline (PBS, Gibco ${ }^{\circledR}$ ) and were placed into a single well of a 24-well plate (Corning, Cambridge, MA). A $1.5 \mathrm{~mL}$ of Roswell Park Memorial Institute medium (RPMI) supplemented with $10 \mathrm{vol} \%$ fetal bovine serum (FBS, Sigma-Aldrich) and $1 \mathrm{vol} \%$ penicillin and streptomycin (Life Technologies) containing $10^{6}$ cells was added to each well. Since it is really difficult to assess the results of $3 \mathrm{D}$ cultures when you use a $2 \mathrm{D}$ culture as control, the non-coated scaffolds were selected to serve as the control material. All samples and controls were incubated at $37^{\circ} \mathrm{C}$ in a humidified atmosphere $\left(5 \% \mathrm{CO}_{2}\right.$ in $95 \%$ air, Steri-Cycle, Thermo Fisher Scientific). Every two days the medium was renewed and the samples were flipped to achieve uniform cell distribution.

Lactate dehydrogenase (LDH) activity. The cell proliferation was evaluated by the LDH assay. To obtain cell lysate, $1 \mathrm{~mL}$ of lysis buffer was added to each well and was left to react for $30 \mathrm{~min}$ at $25^{\circ} \mathrm{C}$. Subsequently, the cell extracts were centrifuged $(2000 \mathrm{r} / \mathrm{min}, 5 \mathrm{~min})$ and
$140 \mu \mathrm{L}$ of the lysed cell solution was added in cuvette to be treated with $60 \mu \mathrm{L}$ of an $\mathrm{LDH}$ assay mixture, which was prepared by mixing an LDH assay substrate solution with LDH assay dye solution and LDH assay cofactor solution (Sigma-Aldrich) in a ratio of 1:1:1. After $30 \mathrm{~min}$ incubation in dark the reaction was stopped by addition of $300 \mu \mathrm{L}$ of hydrochloric acid ( $1 \mathrm{M}$, Sigma-Aldrich). After dilution with $500 \mu \mathrm{L}$ of distilled $\mathrm{H}_{2} \mathrm{O}$, the lysed cells concentrations were determined by absorption measured at $490 \mathrm{~nm}$ and $690 \mathrm{~nm}$ (UV/Vis-spectrometer, Specord 40, Analytik Jena).

Mitochondrial activity. Cellular viability was characterized by their mitochondrial activity using the Water soluble tetrazolium (WST-8) assay. After incubation, $1 \mathrm{~mL}$ of a mixture comprised of 1 vol $\%$ WST- 8 reagent (SigmaAldrich) and 99 vol $\%$ cell culture medium was added to each well plate and were incubated for $90 \mathrm{~min}$ in the $\mathrm{CO}_{2}$-incubator. The quantification of the cell viability was performed by absorption measurements at $450 \mathrm{~nm}$.

Cell morphology. Cell morphologies were characterized by SEM (Quanta 200, FEI, The Netherlands). All samples were washed with PBS, fixed with a solution containing $3 \mathrm{vol} \%$ glutaraldehyde (Sigma, Germany) and 3 vol $\%$ paraformaldehyde (Sigma) in $0.2 \mathrm{M}$ sodium cacodylate buffer (pH 7.4) and finally rinsed three times with PBS. Subsequently, all samples were dehydrated in a graded ethanol series $(30,50,705,80,90,95$, and $99.8 \mathrm{vol} \%)$. Samples were maintained at $99.8 \mathrm{vol} \%$ ethanol and critical-point dried (EM CPD300, Leica, Germany).

Statistical analysis. One-way analysis of variance (ANOVA), Bonferroni's multiple comparison tests, and paired sample T-test were used to determine whether differences in group means were statistically significant. The significance was considered to increase from significant (when $p<0.05$ ) to very significant (when $p<0.01$ ), and highly significant (when $p<0.001$ ).

\section{Mechanical properties investigation}

For the mechanical properties investigation, the scaffolds were observed with an optical microscope and those presenting large flaws were excluded. Ten scaffolds from each category were immediately loaded on a universal testing machine for compression tests (Instron 3344) with a cross-head speed of $0.5 \mathrm{~mm} / \mathrm{min}$ until break. Compression strength was calculated from the ultimate load at fracture and the cross sectional area of the specimens. Paired sample T-test was used to determine whether differences in group means were statistically significant. The significance increased from significant (when $p<0.05$ ), very significant (when $p<0.01$ ), or highly significant (when $p<0.001$ ). 

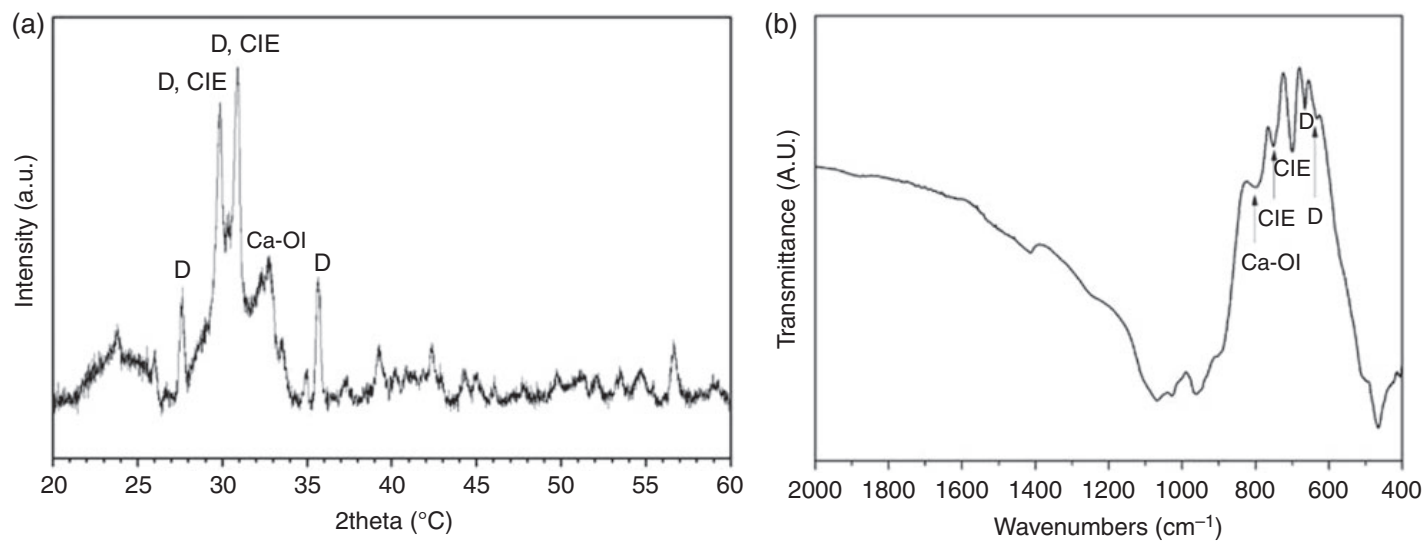

Figure I. (a) XRD pattern and (b) FTIR spectrum of the as-produced sol-gel Mg-based scaffolds. FTIR: Fourier transform infrared spectroscopy; XRD: X-ray diffractometry.

(i)
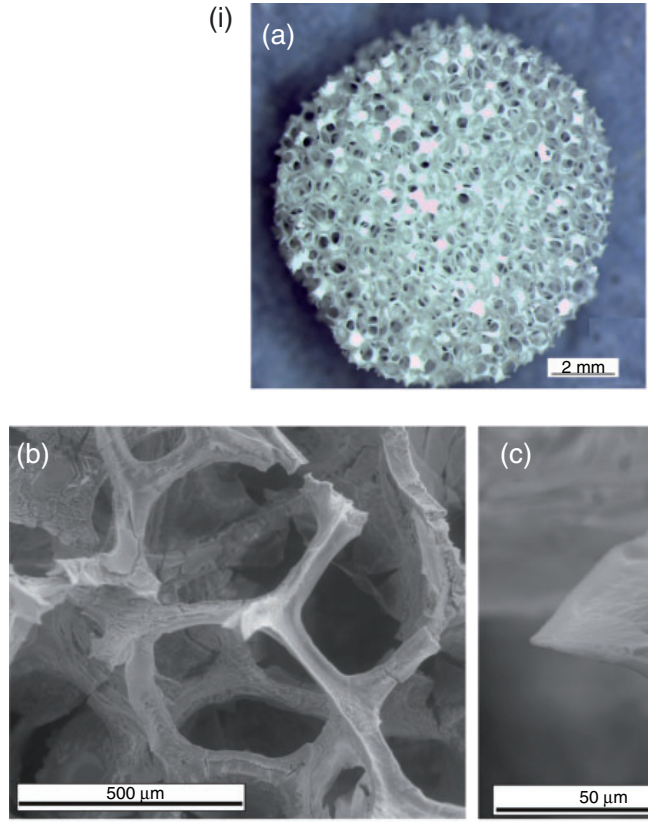

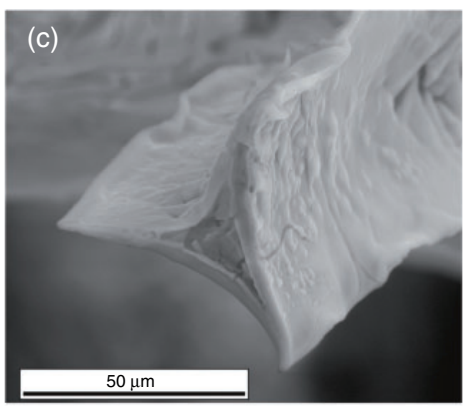

(ii)
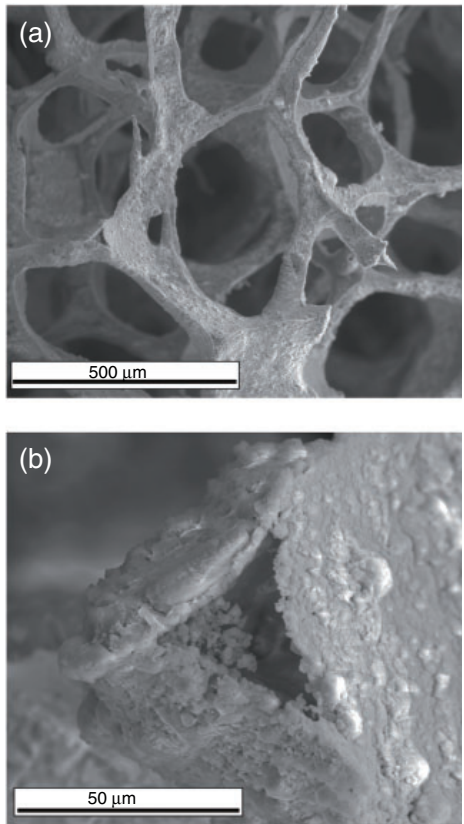

Figure 2. (i) Light microscope (a) and SEM images (b,c) of different magnifications of the non-coated sol-gel derived scaffolds and (ii) SEM images $(a, b)$ of the non-coated scaffolds produced by the traditional foam replica technique.

SEM: scanning electron microscopy.

\section{Results and discussion}

\section{Structural and morphological characterization of the scaffolds}

Structural characterization. The main crystalline phases, as identified by the XRD pattern (Figure 1(a)), were diopside $\left(\mathrm{CaMg}\left(\mathrm{Si}_{2} \mathrm{O}_{6}\right)\right.$, ICDD card 71-1067), clinoenstatite $\left(\mathrm{MgSiO}_{3}, \mathrm{ICDD}\right.$ card 73-1758), and Ca-olivine $\left(\mathrm{Ca}_{2} \mathrm{SiO}_{4}, \mathrm{ICDD}\right.$ card $\left.70-2450\right)$. These results were confirmed by FTIR spectroscopy, since the FTIR spectrum presented the peaks at 665 and $632 \mathrm{~cm}^{-1}$, which have been attributed to diopside ${ }^{20,21}$ as well as the peaks at 700 and $750 \mathrm{~cm}^{-1}$ that can be assigned to clinoenstatite. ${ }^{21,22}$ Finally, even though Ca-olivine has been reported not to present any characteristic bands in the MIR region (4000-400 $\mathrm{cm}^{-1}$ ) of the FTIR spectrum, ${ }^{23,24}$ the peak at $800 \mathrm{~cm}^{-1}$ that can be attributed to the symmetric stretching mode of $\mathrm{Si}-\mathrm{O}$ bonds has been previously connected with the formation of a $\mathrm{Ca}$ olivine phase. ${ }^{23,24}$

Morphological characterization. The morphology and structure of the fabricated sol-gel scaffolds are illustrated in Figure 2(i). It is obvious - and here lies the advantage of the sol-gel technique - that all sol-gel scaffolds present dense struts, which increase their mechanical stability, even though the strut dimensions 

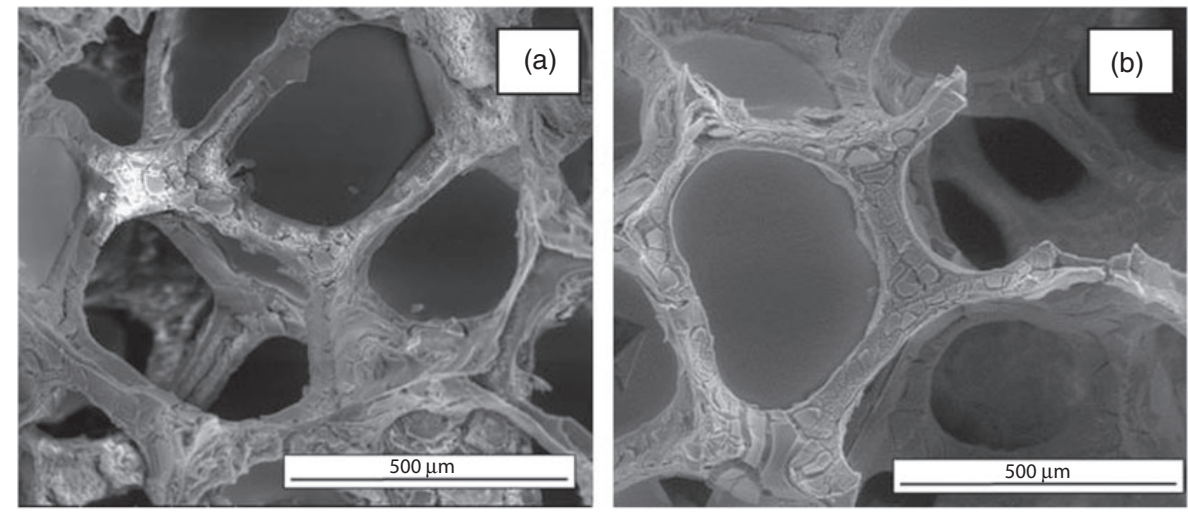

Figure 3. SEM micrographs of the (a) EG- and (b) GG-coated scaffolds.

EG: EDC/NHS cross-linked gelatin; GG: genipin cross-linked gelatin; SEM: scanning electron microscopy.

of the sol-gel scaffolds (Figure 2(i)) are in the same size range of the scaffolds prepared by the traditional foam replica technique (Figure 2(ii)). Furthermore, the pores of all sol-gel scaffolds were completely interconnected exhibiting a porosity of $93 \%( \pm 1)$, while the SEM pictures presented a pore size of about $300-600 \mu \mathrm{m}$ and strut thickness of about $50-100 \mu \mathrm{m}$ (Figure 2(i)). These findings indicated an architecture of adequate porosity and mean pore diameter for cell penetration, vascularization, and nutrient and metabolic waste transportation. ${ }^{7,8,25}$

The architectural characteristics of all scaffolds after being coated with EDC/NHS cross-linked gelatin (EG coating) and genipin cross-linked gelatin (GG coating) are illustrated in Figure 3(i) and (ii), respectively. Both pictures reveal the interconnected and uniform $3 \mathrm{D}$ structure of the coated scaffolds, while their morphology is obviously altered, since the struts are enwrapped by the gelatin layer. Even though some of the pores in the SEM pictures (Figure 3) seem to be blocked by a gelatin layer, the porosity evaluation revealed a mean porosity of $95( \pm 1)$ and $93.3( \pm 0.8)$ for the EG and GG coated samples, respectively.

The importance of scaffold porosity for bone regeneration has been shown by several researchers. ${ }^{1,26,27}$ Porous structures that present a total open porosity of more than $90 \%$ have been proven to promote tissue ingrowth, since they allow cells migration and proliferation as well as matrix deposition in the empty spaces. Furthermore, the presence of an interconnected network of pores facilitates blood vessels invasion and nutrient delivery. ${ }^{7,26-28}$ Finally, the mean pore size plays a fundamental role in bone tissue engineering, since small pores inhibit cell migration and limit the diffusion of nutrients and removal of waste products. ${ }^{29,30}$ On the other hand, too large pores limit cell attachment due to the decrease of the specific surface area. ${ }^{31}$ Even though the optimum mean pore size has not been determined yet and it is bound to depend on the specific tissue to be regenerated, a mean pore diameter of $300-500 \mu \mathrm{m}$ has been recommended by several researchers. ${ }^{7,29}$ On this basis, the scaffolds fabricated in this study present adequate architectural characteristics, since they presented an open, interconnected porosity higher than $90 \%$ and pores' sizes in the range $300-600 \mu \mathrm{m}$.

\section{In vitro apatite-forming ability evaluation}

The FTIR spectra of all three scaffold categories before and after immersion in SBF solution are presented in Figure 4. Before immersion, all spectra show the characteristic peaks of the non-coated scaffold described in "Structural and morphological characterization of the scaffolds" section, since the coating layer was obviously too thin to be detected by the FTIR spectrometer. In all cases, after one day of immersion the formation of peaks at $1100-1035,800$, and $550-600 \mathrm{~cm}^{-1}$ can be observed. These alterations of the FTIR spectra indicate the formation of a $\mathrm{Ca}-\mathrm{P}$ layer on the surface of the scaffold struts after even one day of immersion, while this amorphous $\mathrm{Ca}-\mathrm{P}$ layer is gradually transformed in a hydroxyapatite (HCAp) layer after 10 days of immersion as revealed by the formation of the double peak at $563-603 \mathrm{~cm}^{-1}$ that can be attributed to the $\mathrm{P}-\mathrm{O}$ bending vibration as well as the peak at 1035 assigned to the $\mathrm{P}-\mathrm{O}$ stretching vibration. ${ }^{32}$ Furthermore, the formation of a carbonated layer (HCAp) is supported by the formation of the peaks at 1460 and $870 \mathrm{~cm}^{-1}$ that can be attributed to the stretching and bending vibration, respectively, of the $\mathrm{C}-\mathrm{O}$ bond in the HCAp molecule. ${ }^{33}$

These findings were supported by SEM analysis (Figure 5), which revealed that after 10 days of immersion a thick layer that presents the characteristic morphology of HCAp has covered the entire surface of the struts. Even though, the effectiveness of 

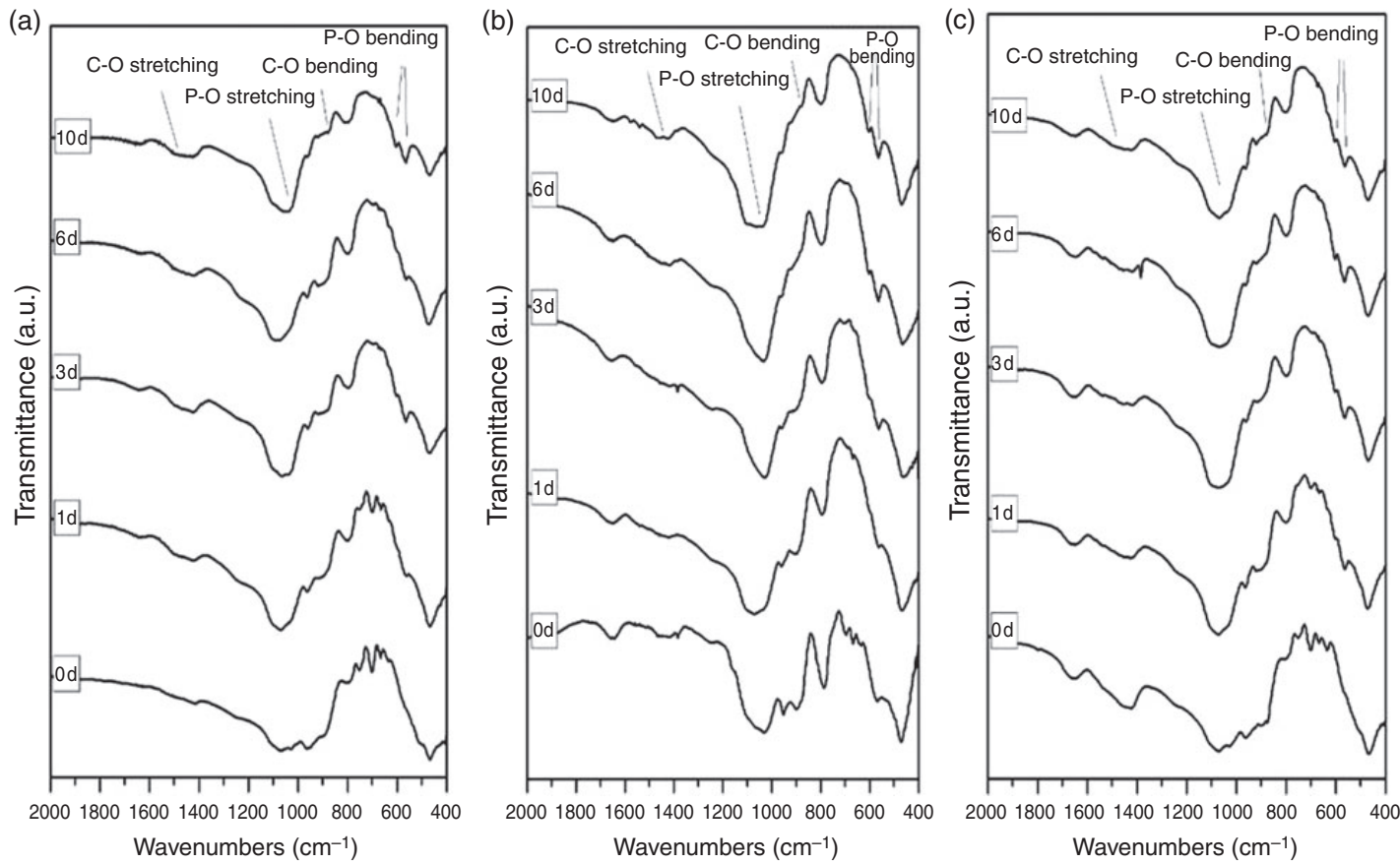

Figure 4. FTIR spectra of the (a) non-coated, (b) EG coated, and (c) GG coated scaffolds before and after immersion in SBF solution. FTIR: Fourier transform infrared spectroscopy; EG: EDC/NHS cross-linked gelatin; GG: genipin cross-linked gelatin; SBF: simulated body fluid.

(a)

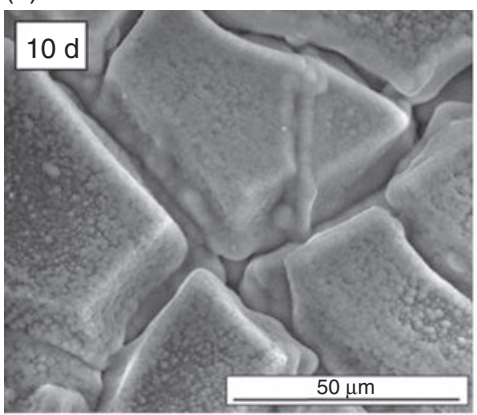

(b)

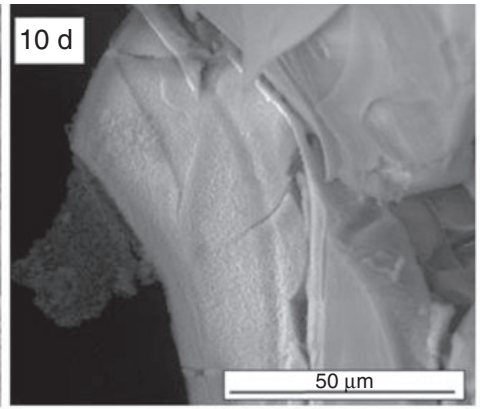

(c)

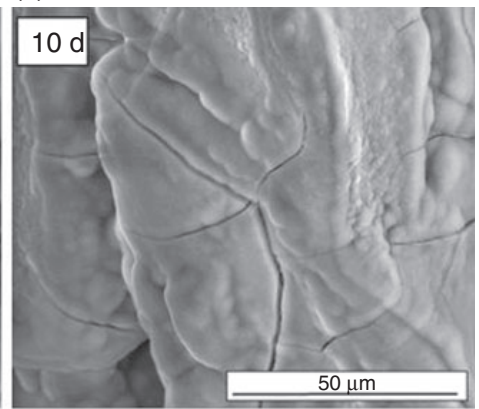

Figure 5. SEM pictures of the (a) non-coated, (b) EG coated, and (c) GG coated scaffolds after immersion in SBF solution for 10 days, showing the formation of a thick apatite layer on the surface of all scaffolds.

EG: EDC/NHS cross-linked gelatin; GG: genipin cross-linked gelatin; SBF: simulated body fluid; SEM: scanning electron microscopy.

bioactivity studies in SBF in predicting bone attachment has been questioned, ${ }^{34}$ the ability of an artificial material to form a carbonated HCAp layer on its surface after immersion in a simulated body fluid solution is a useful indication of bioactive behavior and it is a convenient method to compare the bioreactivity of different materials. ${ }^{35-37}$ Osteoconductivity is a basic requirement for all materials for bone regeneration, since it not only eliminates the formation of fibrous tissue encapsulation but it also promotes the formation of a strong bond between the scaffold and host bone. $^{7}$ Concerning the results of this study, all coated and non-coated scaffolds presented a rather quick surface reactivity in $\mathrm{SBF}$, since the onset of a $\mathrm{Ca}-\mathrm{P}$ layer formation on their surface occurred after one day of immersion and this amorphous layer transformed in HCAp after 10 days of immersion. These results suggest the possible osteoconductive behavior of the synthesized materials and indicate the necessity for further in vitro and in vivo experiments.

\section{Biocompatibility evaluation}

The biocompatibility of the coated and non-coated scaffolds was evaluated colorimetrically. WST analysis 

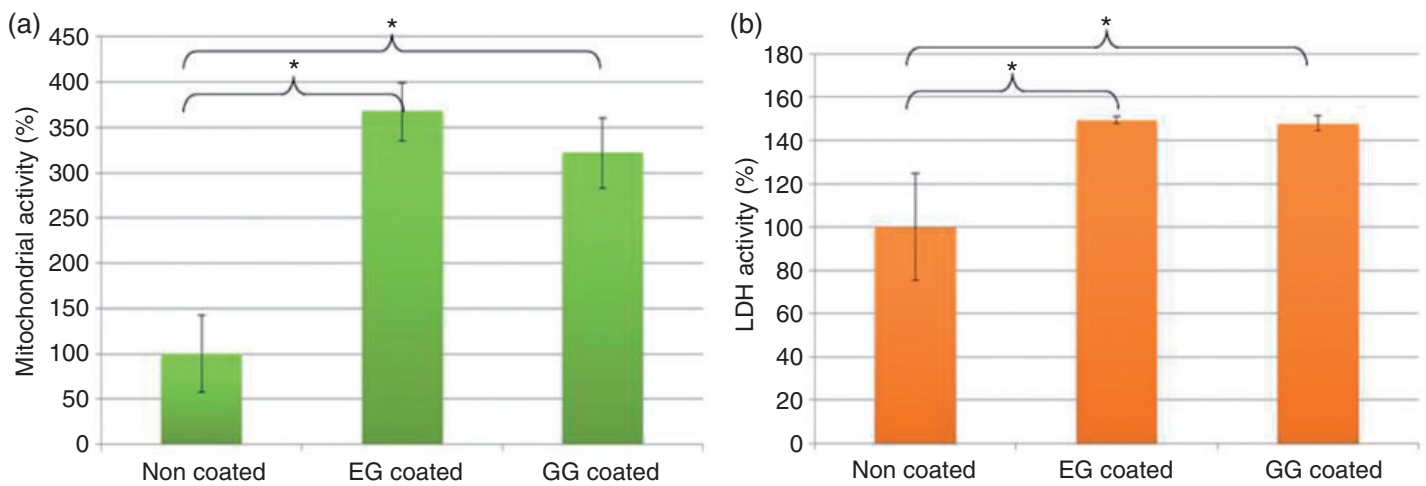

Figure 6. (a) WST analysis and (b) LDH activity of ST-2 stromal cells after incubation with the coated and non-coated scaffolds for 14 days.

LDH: lactate dehydrogenase.

(a)
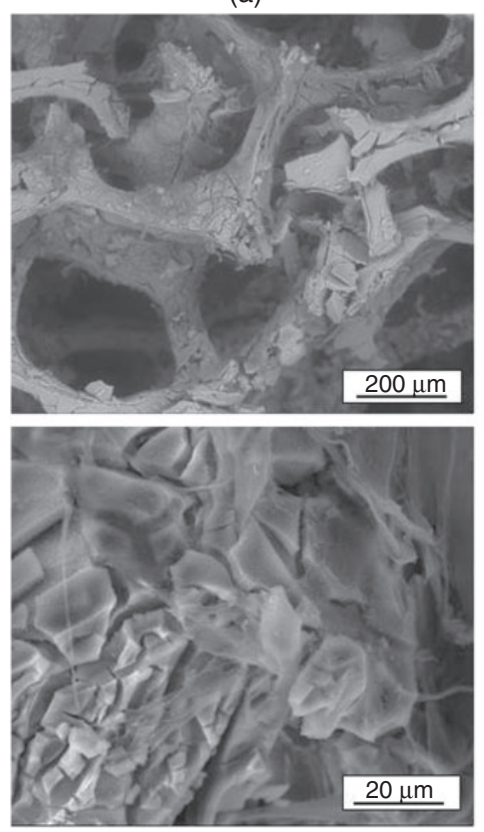

(b)
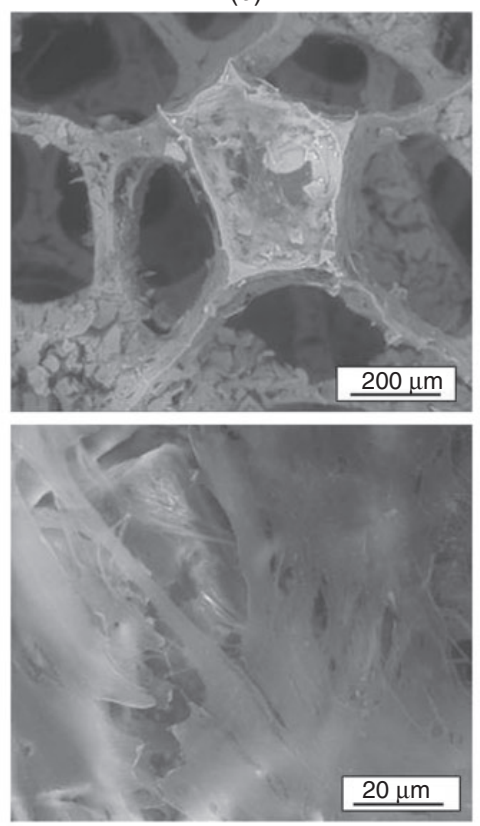

(c)
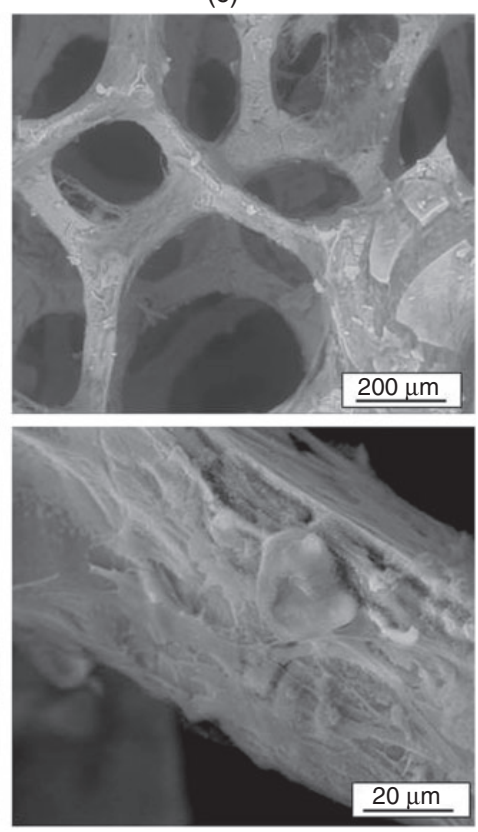

Figure 7. SEM pictures in two magnifications of the (a) non-coated, (b) EG coated, and (c) GG coated scaffolds after incubation with ST-2 stromal cells for 14 days.

EG: EDC/NHS cross-linked gelatin; GG: genipin cross-linked gelatin; SEM: scanning electron microscopy.

was carried out and LDH activity was measured. Normalized results of the coated materials in comparison to the value of the non-coated material are illustrated in Figure 6. Concerning the WST analysis, the values of the coated scaffolds were significantly higher ( $p<<0.001$ in both cases) than the values of the noncoated ones, while EG coated scaffolds presented significantly higher $(p<0.01)$ cell viability than the GG coated scaffold. Furthermore, regarding the LDH activity, both coated scaffolds presented again significantly higher values ( $p=0.027$ and 0.030 for the EG and $\mathrm{GG}$ coating, respectively) than the non-coated scaffolds. However, there were no significant differences $(p=0.862)$ between the mean values of the two different coatings.

The high cell viability in contact with both coated and non-coated scaffolds was further supported by SEM images (Figure 7) which revealed that in all cases the cells have attached and spread on the entire surface of the struts. It seems that mostly in the case of the coated scaffolds, the cultured cells are homogenously distributed over the whole surface of the struts. Apart from specific architectural characteristics and osteoconductivity, a scaffold for bone tissue regeneration should foster cell attachment, differentiation, and proliferation. ${ }^{7,8}$ This requirement was clearly 


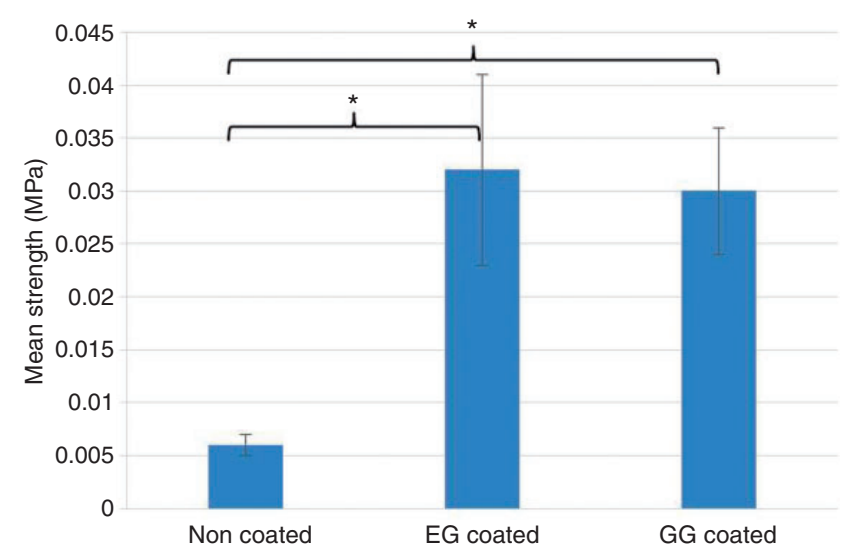

Figure 8. Mean compressive strength values of the coated and non-coated scaffolds.

fulfilled in the case of the synthesized scaffolds of the present study, indicating that the combination of $\mathrm{Mg}$ based silicate scaffolds and gelatin is a promising approach to develop bone tissue scaffolds with sufficient bioactivity and cell attachment ability.

\section{Mechanical properties investigation}

The values of mean compressive strength of all scaffolds are presented in Figure 8. The non-coated scaffolds showed a mean value of $0.006 \pm 0.001 \mathrm{MPa}$, while both GG and EG coated scaffolds presented statistically significant higher ( $p<<0.001$ in both cases) mean values of compressive strength with EG coated scaffolds and GG coated scaffolds presenting values of $0.032 \pm 0.009$ and $0.030 \pm 0.006 \mathrm{MPa}$, respectively. Furthermore, the work of fracture, which is an indication of the brittleness of the material, was significantly $(p<0.001)$ increased from $0.73 \pm 0.23 \mathrm{~J}$ for the uncoated scaffold to $2.95 \pm 0.81$ and $3.50 \pm 1.10 \mathrm{~J}$ for the EG and GG scaffolds, respectively. Finally, it is worth mentioning that, according to preliminary results, the GG coated scaffolds presented a significantly higher mean strength value (data not shown) after incubation with cells for 14 days.

The alveolar bone is a combination of an external cortical plate of dense bone and a trabecular bone occupying the inner area of the alveolar process. ${ }^{4,38}$ The tooth is mainly supported by the bundle bone, which can be defined as the portion of the bone of the alveolar process that surrounds the teeth. The extrinsic collagen fibers of the periodontal ligament (Sharpey's fibers) are embedded within this bundle bone and are running almost perpendicular to the surface of the struts. ${ }^{38,39}$ The strength of the cortical bone as well as the entire mandible has been found to behave anisotropically with the later presenting mean yield compressive stress values of 200,110 , and $100 \mathrm{MPa}$ in longitudinal, tangential and radial direction, respectively. ${ }^{40}$ Due to the anisotropic behavior of the alveolar bone, there is no specific mechanical strength requirement for scaffolds intended for alveolar bone regeneration. Concerning the scaffolds synthesized in the present study, even though the uncoated scaffolds presented originally quite low mean strength values, the presence of gelatin increased significantly the work of fracture as well as the structural integrity of the scaffolds rendering them sufficiently robust for safe handling for further in vitro studies. Furthermore, the compressive strength of scaffolds should increase significantly after incubation with cells as a result of the cells attaching and spreading on the surface of the struts forming a uniform layer that fills the cracks of the material. A second mechanism that can been proposed for the higher compressive strength after incubation is based on the collagen secretion from the cells that has been suggested to attach on bioceramic surfaces and fill surface defects, such as micropores and microcracks. ${ }^{41}$

\section{Conclusions}

This study was undertaken to synthesize $\mathrm{Mg}$-containing silicate scaffolds by the combination of the traditional foam replica and sol-gel techniques that fulfill the basic requirements for bone tissue regeneration, including (a) appropriate architectural characteristics for tissue ingrowth and vascularization, (b) osteoconductivity, (c) biocompatibility, and (d) mechanical stability. Indeed, the fabricated scaffolds presented a 3D interconnected pore network and a total porosity of more than $90 \%$, while the in vitro apatite formation ability evaluation of all scaffolds indicated the formation of apatite on the scaffold surfaces after 10 days of immersion in SBF, indicating the osteoconductive character of the scaffolds Concerning the third requirement, all materials were proven to promote attachment, spreading, and proliferation of ST-2 stromal cells. Finally, even though all materials presented relatively low compressive strength, the mechanical stability was enhanced by the presence of gelatin. It was also found that the mechanical strength of the scaffolds could be significantly improved after incubation with cells. However, this is a point of interest for future work.

\section{Acknowledgements}

The authors of this work would like to thank Prof Ben Fabry, Biophysics group, University of Erlangen-Nuremberg for giving us access to his laboratory facilities.

\section{Declaration of Conflicting Interests}

The author(s) declared no potential conflicts of interest with respect to the research, authorship, and/or publication of this article. 


\section{Funding}

The author(s) disclosed receipt of the following financial support for the research, authorship, and/or publication of this article: This work was funded by a Marie Curie IntraEuropean Fellowship (PIEF-GA-2011-298295).

\section{References}

1. Eke PI, Dye BA, Wei L, et al. Cdc Periodontal Disease Surveillance workgroup: James Beck GDRP. Prevalence of periodontitis in adults in the United States: 2009 and 2010. J Dent Res 2012; 91: 914-920.

2. Reich BJ, Bandyopadhyay D and Bondell HD. A nonparametric spatial model for periodontal data with non-random missingness. J Am Stat Assoc 2013; 108: 503-523.

3. Loesche WJ and Grossman NS. Periodontal disease as a specific, albeit chronic, infection: diagnosis and treatment. Clin Microbiol Rev 2001; 14: 727-752. (table of contents).

4. Chen FM and Jin Y. Periodontal tissue engineering and regeneration: current approaches and expanding opportunities. Tissue Eng B Rev 2010; 16: 219-255.

5. Bashutski JD and Wang HL. Periodontal and endodontic regeneration. J Endod 2009; 35: 321-328.

6. Bartold PM, McCulloch CA, Narayanan AS, et al. Tissue engineering: a new paradigm for periodontal regeneration based on molecular and cell biology. Periodontology 2000; 24: 253-269.

7. Chen Q, Roether JA and Boccaccini AR. Tissue engineering scaffolds from bioactive glass and composite materials. In: Ashammakhi N, Reis R and Chiellini F (eds) Topics in Tissue Engineering, Vol. 4. Oulu, Finland (e-book), 2008.

8. Hutmacher DW. Scaffolds in tissue engineering bone and cartilage. Biomaterials 2000; 21: 2529-2543.

9. Goudouri O-M, Kontonasaki E, Chrissafis K, et al. Towards the synthesis of an Mg-containing silicate glass-ceramic to be used as a scaffold for cementum/ alveolar bone regeneration. Ceramics Int 2014; 40: 16287-16298.

10. Wu F, Liu C, O’Neill B, et al. Fabrication and properties of porous scaffold of magnesium phosphate/polycaprolactone biocomposite for bone tissue engineering. Appl Surface Sci 2012; 258: 7589-7595.

11. Karageorgiou V and Kaplan D. Porosity of 3D biomaterial scaffolds and osteogenesis. Biomaterials 2005; 26 : 5474-5491.

12. Diba M, Tapia F, Boccaccini AR, et al. Magnesiumcontaining bioactive glasses for biomedical applications. Int J Appl Glass Sci 2012; 3: 221-253.

13. Zhuang H, Han Y and Feng A. Preparation, mechanical properties and in vitro biodegradation of porous magnesium scaffolds. Mater Sci Eng C 2008; 28: 1462-1466.

14. Al-Noaman A, Rawlinson SCF and Hill RG. The role of $\mathrm{MgO}$ on thermal properties, structure and bioactivity of bioactive glass coating for dental implants. J Non-crystalline Solids 2012; 358: 3019-3027.

15. Chen QZ, Thompson ID and Boccaccini AR. 45S5 Bioglass ${ }^{\circledR}$-derived glass-ceramic scaffolds for bone tissue engineering. Biomaterials 2006; 27: 2414-2425.
16. Mohamad Yunos D, Bretcanu $\mathrm{O}$ and Boccaccini A. Polymer-bioceramic composites for tissue engineering scaffolds. J Mater Sci 2008; 43: 4433-4442.

17. Saravanapavan $P$ and Hench LL. Low-temperature synthesis, structure, and bioactivity of gel-derived glasses in the binary $\mathrm{CaO}-\mathrm{SiO} 2$ system. J Biomed Mater Res 2001; 54: 608-618.

18. Saravanapavan P, Jones JR, Pryce RS, et al. Bioactivity of gel-glass powders in the $\mathrm{CaO}-\mathrm{SiO} 2$ system: a comparison with ternary (CaO-P2O5-SiO2) and quaternary glasses (SiO2-CaO-P2O5-Na2O). J Biomed Mater Res A 2003; 66: 110-119.

19. Kokubo T, Kushitani H, Sakka S, et al. Solutions able to reproduce in vivo surface-structure changes in bioactive glass-ceramic A-W. J Biomed Mater Res 1990; 24: 721-734.

20. R. D. The RRUFF Project: an integrated study of the chemistry, crystallography. Raman and infrared spectroscopy of minerals. In: 19th Meneral Meeting of the International Mineralogical Association, Kobe, Japan, 23-28 July 2006, pp.3-13.

21. Kalinkina EV, Kalinkin AM, Forsling W, et al. Sorption of atmospheric carbon dioxide and structural changes of $\mathrm{Ca}$ and $\mathrm{Mg}$ silicate minerals during grinding: I. Diopside. Int J Mineral Processing 2001; 61: 273-288.

22. Kalinkina EV, Kalinkin AM, Forsling W, et al. Sorption of atmospheric carbon dioxide and structural changes of $\mathrm{Ca}$ and $\mathrm{Mg}$ silicate minerals during grinding: II. Enstatite, åkermanite and wollastonite. Int $J$ Mineral Processing 2001; 61: 289-299.

23. Laudisio G and Branda F. Sol-gel synthesis and crystallisation of $3 \mathrm{CaO} \cdot 2 \mathrm{SiO} 2$ glassy powders. Thermochim Acta 2001; 370: 119-124.

24. Goudouri OM, Theodosoglou E, Papadopoulou L, et al. The impact of stirring rate on the crystallinity and bioactivity of 58S bioactive glass. Key Eng Mater 2011; 493498: 43-48.

25. Wu C, Chang J, Zhai W, et al. Porous akermanite scaffolds for bone tissue engineering: preparation, characterization, and in vitro studies. J Biomed Mater Res B 2006; 78B: 47-55.

26. Bobyn JD, Pilliar RM, Cameron HU, et al. The optimum pore size for the fixation of porous-surfaced metal implants by the ingrowth of bone. Clin Orthop Relat Res 1980; 263-270.

27. Eggli PS, Muller W and Schenk RK. Porous hydroxyapatite and tricalcium phosphate cylinders with two different pore size ranges implanted in the cancellous bone of rabbits. A comparative histomorphometric and histologic study of bony ingrowth and implant substitution. Clin Orthop Relat Res 1988; 127-138.

28. Daculsi G and Passuti N. Effect of the macroporosity for osseous substitution of calcium phosphate ceramics. Biomaterials 1990; 11: 86-87.

29. Murphy CM and O'Brien FJ. Understanding the effect of mean pore size on cell activity in collagenglycosaminoglycan scaffolds. Cell Adhes Migr 2010; 4: 377-381.

30. O'Brien FJ, Harley BA, Waller MA, et al. The effect of pore size on permeability and cell attachment in collagen 
scaffolds for tissue engineering. Technol Health Care 2007; 15: 3-17.

31. Yannas IV. Tissue regeneration by use of collagen-glycosaminoglycan copolymers. Clin Mater 1992; 9: 179-187.

32. Clupper DC and Hench LL. Bioactive response of Agdoped tape cast Bioglass ${ }^{\circledR}$ 45S5 following heat treatment. J Mater Sci 2001; 12: 917-921.

33. Ślósarczyk A, Paszkiewicz Z and Paluszkiewicz C. FTIR and XRD evaluation of carbonated hydroxyapatite powders synthesized by wet methods. J Mol Struct 2005; 744 747: 657-661.

34. Bohner M and Lemaitre J. Can bioactivity be tested in vitro with SBF solution? Biomaterials 2009; 30: 2175-2179.

35. Kokubo T. Bioactive glass ceramics: properties and applications. Biomaterials 1991; 12: 155-163.

36. Al-Mahmood Tarique A, Tsuru K, Maruta M, et al. In vitro osteoconductivity evaluation of alumina treated hydrothermally in $\mathrm{CaCl}_{2}$ solution. $J$ Ceram Soc Japan 2010; 118: 512-515.
37. Cho JS, Yoo DS, Chung Y-C, et al. Enhanced bioactivity and osteoconductivity of hydroxyapatite through chloride substitution. J Biomed Mater Res A 2014; 102: 455-469.

38. Nanci A and Bosshardt DD. Structure of periodontal tissues in health and disease. Periodontology 2000 2006; 40: $11-28$

39. Araujo MLJ. The edentulous alveolar ridge. In: Lindhe JKT, Lang N (eds) Clinical periodontology and implant dentistry. Oxford: Blackwell Munksgaard, 2003, pp.53-63.

40. van Eijden TM. Biomechanics of the mandible. Crit Rev Oral Biol Med 2000; 11: 123-136.

41. Chen QZ, Efthymiou A, Salih V, et al. Bioglass ${ }^{\circledR}$-derived glass-ceramic scaffolds: study of cell proliferation and scaffold degradation in vitro. $J$ Biomed Mater Res A 2008; 84: 1049-1060. 